\title{
Presynaptic NR2A-Containing NMDARs Are Required for LTD between the Amygdala and the Perirhinal Cortex: A Potential Mechanism for the Emotional Modulation of Memory? ${ }^{1,2,3}$
}

\author{
D. Michael D. Laing, ${ }^{1}$ and Zafar I. Bashir ${ }^{2}$ \\ DOI:http://dx.doi.org/10.1523/ENEURO.0046-14.2015 \\ ${ }^{1}$ Neuroscience and Mental Health Research Institute, Hadyn Ellis Building, Cathays, Cardiff, CF24 4HQ, United \\ Kingdom, ${ }^{2}$ School of Physiology and Pharmacology, Bristol University, Bristol, BS8 1TD, United Kingdom
}

\begin{abstract}
Visual recognition memory relies on long-term depression-like mechanisms within the perirhinal cortex and the activation of the lateral amygdala can enhance visual recognition memory. How the lateral amygdala regulates recognition memory is not known, but synaptic plasticity at amygdala - perirhinal synapses may provide a mechanism for the emotional enhancement of recognition memory. In this study, we investigate the mechanisms of long-term depression (LTD) at the amygdala- perirhinal synapse in male Lister Hooded rats. We demonstrate that LTD at this input relies on NR2A-containing NMDARs, located presynaptically. Therefore, the underlying mechanisms of LTD, at the amygdala-perirhinal input, which may regulate the emotional context for recognition memory, are different to previously described postsynaptic NR2B-NMDAR mechanisms of intraperirhinal LTD that subserve recognition memory.
\end{abstract}

Key words: amygdala; emotion; memory; perirhinal; plasticity; transmission

\section{Significance Statement}

Emotional events are better remembered than emotionally neutral events. The ability of memory enhancement by emotion is dependent on amygdala-mediated alterations of synaptic activity. The amygdala has robust connections with perirhinal cortex, modulating synaptic transmission and plasticity within this region. The perirhinal cortex is necessary for visual object recognition, relying on long-term depression for memory. Despite the importance of emotion to modulate memory in perirhinal cortex, the mechanisms are unknown. We provide the first demonstration of the mechanisms underlying LTD at this synapse, dependent on presynaptically located NR2A-containing NMDARs. We show a role for NMDARs in amygdala-perirhinal plasticity, and that the mechanisms described here are different to those of amygdala-perirhinal LTP (NMDAR-independent) and intraperirhinal plasticity (NMDAR-dependent), both of which are induced postsynaptically.

\section{Introduction}

The familiarity discrimination component of visual recognition memory requires the perirhinal cortex, as demon-

Received October 23, 2014; accepted February 23, 2015; First published February 25, 2015.

${ }^{1}$ Authors report no conflict of interest.

${ }^{2}$ Author Contributions: M.D.L. and Z.I.B. designed research; M.D.L. performed research; M.D.L. analyzed data; M.D.L. wrote the paper.
${ }^{3}$ We thank the Medical Research Council for their financial support. In addition, we thank Vincenzo Crunelli for his comments on the manuscript. Correspondence should be addressed to Michael Laing, Neuroscience and Mental Health Research Institute, Hadyn Ellis Building, Maindy Road, Cardiff University, Cardiff, CF24 4HQ. E-mail: LaingM@cardiff.ac.uk

DOl:http://dx.doi.org/10.1523/ENEURO.0046-14.2015 Copyright (c) 2015 Laing and Bashir

This is an open-access article distributed under the terms of the Creative Commons Attribution 4.0 International, which permits unrestricted use, distribution and reproduction in any medium provided that the original work is properly attributed. 
strated in both macaque (Gaffan and Murray, 1992; Fahy et al., 1993; Suzuki et al., 1993; Suzuki, 1996; Murray and Bussey, 1999) and rodent (Aggleton et al., 1997; Ennaceur and Aggleton, 1997; Ennaceur et al., 1997; Dix and Aggleton, 1999; Winters et al., 2004) models, relying on lasting decrements in neuronal activation (Zhu and Brown, 1995; Brown and Xiang, 1998). There is a clear evidence that synaptic plasticity in the perirhinal cortex may provide the cellular mechanisms underlying recognition memory (Warburton et al., 2003; Griffiths et al., 2008; Massey et al., 2008).

Experiences with a high degree of emotional salience are better remembered than emotionally neutral events and this enhancement of memory may be mediated through actions of the lateral amygdala (Roozendaal et al., 2008). The strong reciprocal connectivity between the lateral amygdala and the perirhinal cortex (Pitkänen et al., 2000; Kajiwara et al., 2003) provides an anatomical basis by which the lateral amygdala may profoundly influence mechanisms of recognition memory. Indeed, inputs from the lateral nucleus of the amygdala (Furtak et al., 2007) directly influence perirhinal cortex activity and regulate synaptic transmission between the perirhinal cortex and the entorhinal cortex (Paz et al., 2006). However, the receptor mechanisms by which the lateral amygdala might modulate synaptic plasticity, and learning and memory, have not yet been fully elucidated.

A recent publication has described the mechanisms of long-term potentiation (LTP) at amygdala-perirhinal synapses (Laing and Bashir, 2014). However, the mechanisms of long-term depression (LTD) induction at the input from the lateral amygdala to the perirhinal cortex have not been investigated. These mechanisms are important to determine since LTD-like mechanisms are critical in perirhinal cortex-dependent recognition memory (Warburton, et al., 2003; Griffiths, et al., 2008; Massey, et al., 2008). Therefore, the aim of this study was to examine in an in vitro brain slice preparation the receptors required for amygdala-perirhinal LTD and whether there is an overlap between the mechanisms required for amygdala- perirhinal LTP and intracortical plasticity.

\section{Materials and Methods}

Juvenile male Lister Hooded rats $30-35$ d of age (80$100 \mathrm{~g}$; Harlan Laboratories) were maintained on a $12 \mathrm{~h}$ light/12 h dark cycle (dark phase during normal daylight). All animal procedures are performed according to the regulation of authors' university's animal care committee.

\section{Slice preparation and electrophysiology}

Animals were anesthetized with an isoflurane/oxygen mixture and decapitated, and the brain was rapidly removed. The brain was placed in ice-cold artificial CSF (aCSF; bubbled with $95 \% \mathrm{O}_{2} / 5 \% \mathrm{CO}_{2}$ ), which comprised the following (in $\mathrm{mM}$ ): $124 \mathrm{NaCl}, 3 \mathrm{KCl}, 26 \mathrm{NaHCO}_{3}, 1.25$ $\mathrm{NaH} 2 \mathrm{PO}_{4}, 2 \mathrm{CaCl}_{2}, 1 \mathrm{MgSO}_{4}$, and $10 \mathrm{D}$-glucose. The olfactory bulb, the cerebellum, and the brain stem were removed. A horizontal cut was made anterior to posterior on the ventral surface of the brain. This created a flat surface by which the brain was glued, ventral side down, to the vibroslice stage. Ventral slices (400 $\mu \mathrm{m}$ thick) con- tained area 35 of perirhinal cortex and the lateral nucleus of the amygdala; the most dorsal slice also contained area 36 . Slices were stored submerged in aCSF $\left(20-25^{\circ} \mathrm{C}\right)$ for at least $1 \mathrm{~h}$ before transferring to the recording chamber. A single slice was placed in a submerged recording chamber and perfused with aCSF $\left(30-32{ }^{\circ} \mathrm{C}\right.$; flow rate 2 $\mathrm{ml} / \mathrm{min})$.

\section{Whole-cell recordings}

Recording electrodes (pulled on Sutter Instruments $\mathrm{P}-87$ puller) were filled with intracellular solution [(in $\mathrm{mM}$ ): $\mathrm{CsMeSO}_{4}$ 130, HEPES 10, EGTA 0.5, MgATP 4, NaGTP $0.3, \mathrm{QX}^{-314}-\mathrm{Cl}^{-} 5, \mathrm{NaCl} 8$ (280-300 mOsm, pH 7.2)] and were of 2.5-4 $\mathrm{M} \Omega$ resistance. Excitatory postsynaptic currents were evoked by a bipolar stimulation electrode (frequency of simulation: $0.033 \mathrm{~Hz}$ ) placed in the lateral amygdala (designated the LA-PRh input). Whole-cell recordings were made from layer II/III neurons and, unless otherwise stated, the cells were voltage clamped at -70 $\mathrm{mV}$ during recording. To induce LTD, a low-frequency stimulation protocol (LFS; 200 stimuli, $1 \mathrm{~Hz}$ ) was paired with depolarisation of the cell to $-40 \mathrm{mV}$ by injection of Direct current (DC) through the recording pipette. Recordings were made using an Axopatch 200B amplifier (Molecular Devices). Amplitudes of the evoked EPSCs were measured and expressed relative to the normalised baseline (see Analysis section). The data was acquired using WinLTP (v2.01). Recordings were filtered at $5 \mathrm{kHz}$ and digitized at $20 \mathrm{kHz}$ (Digidata 1322A; Molecular Devices). Only cells that had a series resistance $\left(R_{\mathrm{S}}\right)<25 \mathrm{M} \Omega$ and $<25 \%$ change in the $R_{\mathrm{S}}$ during the course of the experiment were included for analysis. Postsynaptic blockade of NMDARs was achieved by adding (+)-MK-801 maleate $(3 \mathrm{mM})$ to the intracellular filling solution. To ensure MK801 blockade of postsynaptic NMDARs, the cells were briefly depolarised to $-10 \mathrm{mV}$ between stimulations to relieve the magnesium block and aid in MK-801 entry. All cells were patched for a minimum of 20 min prior to the induction of LTD. For experiments recording NMDAR EPSCs, the slice was continuously perfused with NBQX (5 $\mu \mathrm{M})$ and picrotoxin $(50 \mu \mathrm{M})$.

\section{Pharmacological agents}

Unless otherwise stated, all compounds were obtained from Tocris Bioscience and were prepared as stock solutions $(1-10 \mathrm{mM})$ by dilution in double-distilled water and aliquoted for storage at $-20^{\circ} \mathrm{C}$. The following compounds were diluted in aCSF and bath applied at the following concentrations: RO 25-6981 maleate (1 $\mu \mathrm{M})$, picrotoxin $(50 \mu \mathrm{M}), \mathrm{NBQX}(5 \mu \mathrm{M})$, D-AP5 $(50 \mu \mathrm{M})$, propranolol hydrochloride $(500 \mathrm{nM})$, verapamil hydrochloride $(20 \mu \mathrm{M})$, TCN-201 $(10 \mu \mathrm{M})$, NVP-AAM077 (200 nM), and $\mathrm{L}-689,560(5 \mu \mathrm{M})$.

\section{Analysis}

The peak amplitude of EPSCs were normalised to an initial $10 \mathrm{~min}$ baseline. When experiments were pooled together to generate summary graphs, the mean and the SEM $( \pm)$ were calculated from the pooled data sets. For statistical analysis, the last $10 \mathrm{~min}$ of the baseline were compared to the last $10 \mathrm{~min}$ of the protocol. Therefore, 
statistics based on LTD refer to statistical significance 30 min after LFS. For comparison between two different conditions, an unpaired student's $t$ test was performed. For this, the normalised pooled data was used to run statistical comparisons between the two different groups. To study a before and after effect (e.g., baseline vs LFS) within the same group, a paired Student's $t$ test was performed. In all cases a superscript letter follows the associated $p$ value. This relates to the statistical figure on page 7 . In all experiments, $N$ is equal to the number of rats euthanized for that experiment. The paired-pulse facilitation was determined by expressing the amplitude of the second response as a proportion of the amplitude of the first response. Statistics and graphs were generated using SigmaPlot V12.5. The software was also used to test for normality, using the Shapiro-Wilk test.

\section{Results}

\section{LTD at the LA-PRh input relies on activation of NMDARs}

Whole-cell recordings were made from Layer II/III neurons in perirhinal cortex (PRh) and voltage-clamped at $-70 \mathrm{mV}$, unless otherwise stated. Stimuli were delivered every $30 \mathrm{~s}$ to the lateral amygdala (LA) to evoke EPSCs in the recorded cell (Fig. 1A). After obtaining a stable baseline of $10 \mathrm{~min}, 200$ stimuli were delivered at $1 \mathrm{~Hz}$ (lowfrequency stimulation; LFS) while maintaining a holding potential of $-40 \mathrm{mV}$. The use of this protocol consistently produced robust LTD (depression to $50 \pm 5 \%$ of baseline, $p=0.0045^{\mathrm{a}}, N=6$; Fig. $1 B$ ). To ensure that the conditions of recording did not produce rundown of synaptic transmission, control experiments were intercalated with the LTD experiments (Fig. 1B, white circles). Under these conditions, no significant reduction in baseline was observed $\left(100 \pm 6 \%\right.$, df $=5, p=0.6, N=6$, Fig. $\left.1 B^{\mathrm{b}}\right)$. It has been demonstrated that beta adrenoceptors ( $\beta$ ADRs) and voltage-gated calcium channels (VGCCs) are required for the induction of LTP at the LA-PRh input (Perugini et al., 2012). In contrast to the mechanisms of amygdala-perirhinal LTP, we observed that the induction and maintenance of LTD was not blocked by the $\beta$-ADR antagonist propranolol (depression to $39 \pm 9 \%$ of baseline, $\mathrm{df}=3, p=0.01^{\mathrm{c}}, N=4$; Fig. $1 C$ ) nor by the VGCC inhibitor verapamil $\left(52 \pm 12 \%\right.$, df $=6, p=0.0089^{d}, N=$ 7 ; Fig. 1D). Since the perirhinal cortex can utilise NMDARs for the induction of LTD (Cho et al., 2000), we questioned whether amygdala-perirhinal LTD may similarly be NMDAR-dependent.

Bath application of the nonspecific NMDAR antagonist (Monaghan and Jane, 2009) D-AP5 (50 $\mu \mathrm{M})$ blocked the induction of $\operatorname{LTD}\left(90 \pm 4 \%\right.$, df $=5, p=0.16^{\mathrm{e}}, N=6$; Fig. $1 E)$. To confirm this observation, a structurally dissimilar NR1-selective antagonist, L-689,560 (5 $\mu \mathrm{M})$ (Yao and Mayer, 2006), was bath applied. This antagonist, which acts at the glycine-binding site of the NMDAR, also blocked the induction of LTD $\left(99 \pm 3 \%\right.$, df $=3, p=0.41^{\mathrm{f}}$, $N=4$; Fig. $1 F$ ). These results demonstrated that the receptors required for the induction of LTD at the LA-PRh synapse are different to the mechanisms of induction of LTP at the LA-PRh input (Laing and Bashir, 2014).

\section{LTD at the LA-PRh input relies on presynaptic NMDARs}

Previous studies have shown that postsynaptic NMDARs are required for the induction of LTD at intraperirhinal synapses (Massey et al., 2004). We therefore examined whether the NMDARs required for the induction of LTD at the LA-PRh input were postsynaptically or presynaptically located. To specifically block postsynaptic NMDARs, MK-801 (3 mM) was added to the internal patch solution and cells were allowed a minimum of $20 \mathrm{~min}$ to equilibrate prior to LTD induction. MK-801 displays an $\mathrm{IC}_{50}$ of $0.01 \mu \mathrm{M}$ for both NR1/NR2A and NR1/NR2B; we therefore expected this compound to inhibit all postsynaptic NMDARs (Paoletti and Neyton, 2007). However, under these conditions, LTD was not blocked (depression to $63 \% \pm 5 \%$, df $=8, p=0.029^{9}, N=9$; Fig. $2 A$ ) and the magnitude of LTD was not significantly different $(p=$ $0.92^{\mathrm{h}}$ ) from control LTD (Fig. 1B). To ensure that under the conditions of our experiments, NMDA EPSCs were blocked by MK-801, cells were patched with internal MK-801 while AMPAR and GABAR-mediated transmission were blocked with bath application of NBQX and picrotoxin, respectively; in these experiments, no NMDA EPSCs could be observed ( $N=6$; Fig. $\left.2 B, B 2, \mathrm{~B}^{3}\right)$. In separate control experiments, NMDA EPSCs were consistently evoked by LA stimulation in the absence of internal MK-801 (Fig. 2B, B1, $\mathrm{B}^{3}$ ). Statistical analysis of $-40 \mathrm{mV}(N=10)$ against $-40 \mathrm{mV}$ in the presence of intracellular MK-801 ( $N=6)$ yielded statistical significance $\left(p=0.015^{i}\right)$. Similarly, the comparison of NMDAR peak amplitude between $+40 \mathrm{mV}(N=10)$ and $+40 \mathrm{mV}$ in the presence of MK-801 $(N=6)$ was significant $(p \leq$ $\left.0.0001^{j}\right)$.

To further examine a possible role for postsynaptic NMDARs in LTD at the LA-PRh input, neurons were hyperpolarised by $\mathrm{DC}$ injection to $-90 \mathrm{mV}$ during the delivery of LFS to sustain the $\mathrm{Mg}^{2+}$ block of the NMDAR pore. However, this manipulation did not prevent the induction of LTD $\left(50 \% \pm 8.4 \%\right.$, df $=2, p=0.028^{\mathrm{k}}, \mathrm{N}=$ 3; Fig. 2C). To further corroborate our findings, an experiment was performed in which the calcium chelator BAPTA (3 mM) was included in the internal patch solution. For these experiments, the LFS was paired with a holding command of $-40 \mathrm{mV}$. Under these conditions, we still observed that LFS induced LTD $(49 \% \pm 7 \%$, df $=9, p \leq$ 0.0001', $N=10$; Fig. 2D).

Together, the above results demonstrated that LTD at the LA-PRh input did not require postsynaptic NMDARs, and additionally indicated that a postsynaptic increase in calcium (from some source other than NMDARs) was not required for $L T D$. This suggested that the mechanism of LTD at LA-PRh synapses most likely relies on presynaptic NMDARs and is therefore different to LTD at intracortical PRh synapses (Massey et al., 2004).

\section{NR2A-containing NMDARs are necessary for LTD}

Previous studies have suggested a role for presynaptic NR2B-containing NMDARs in the induction of LTD in rat neocortex (Sjöström et al., 2003). Therefore, we investigated whether the induction of LA-PRh LTD was sensi- 
A

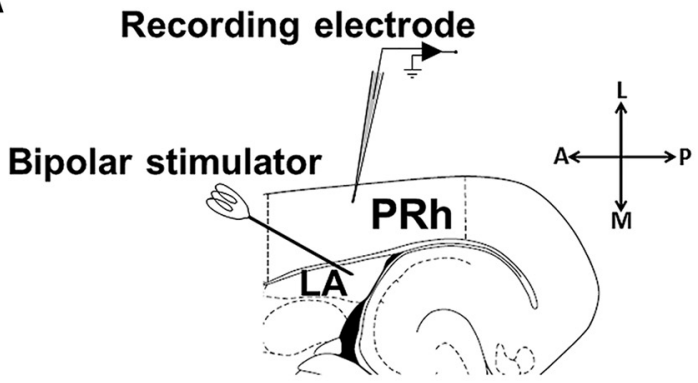

C

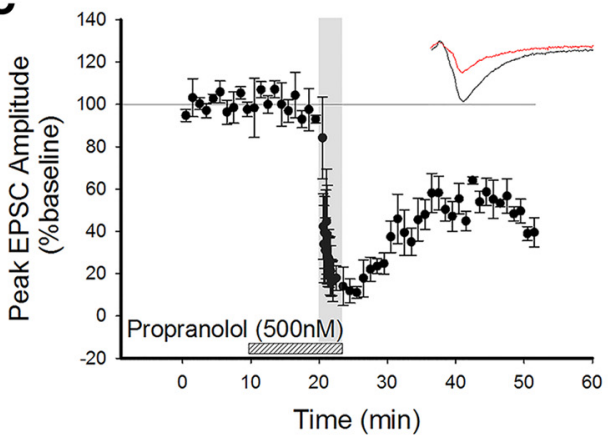

E

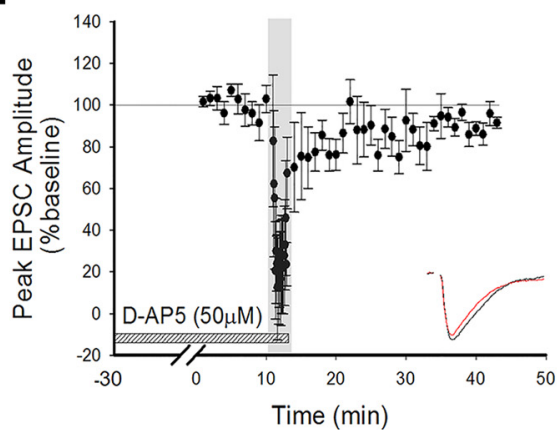

B

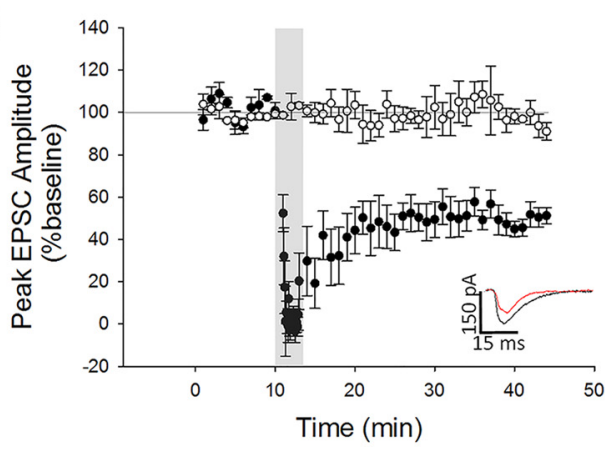

D

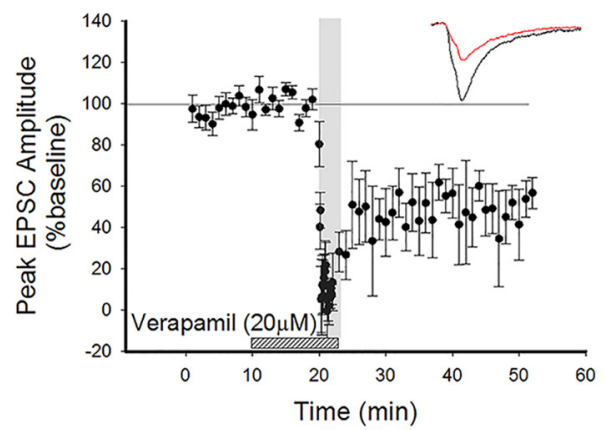

F

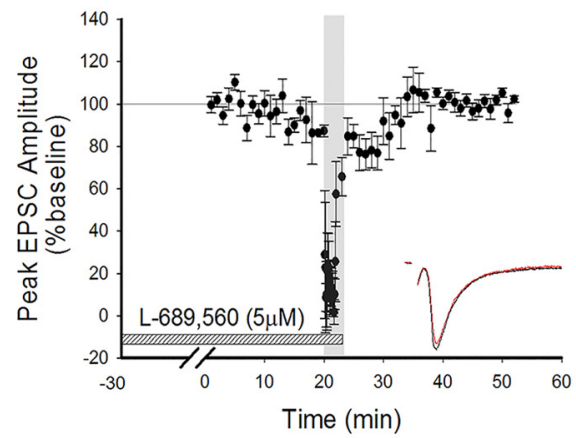

Figure 1 LTD is NMDAR-dependent, but is not dependent on $\beta$-ADRs or VGCCs. $\boldsymbol{A}$, Schematic diagram highlighting the recording and stimulating positions within the horizontal slice preparation with LA and PRh highlighted. L, Lateral; $A$, anterior; M, medial; $P$, posterior. B, Pooled data showing induction of LTD by LFS (200 pulses at $1 \mathrm{~Hz}$, black circles) during application of a holding potential to $-40 \mathrm{mV}$. Intercalated control experiments are presented as white circles. Inserts here and all graphs show response traces during baseline (black) and following manipulation (red). In all cases, the scale bar dimensions remain the same (150 pA by $15 \mathrm{~ms})$. Dotted horizontal lines act as a visual aid to the $100 \%$ baseline and the gray vertical bars represent the period of LFS delivery. C, Pooled data highlighting that blockade of $\beta$-ADRs with propranolol did not prevent the induction of LTD. D, Pooled data showing that LTD induction was not dependent on VGCCs. $\boldsymbol{E}$, Pooled data highlighting that bath application of D-AP5 prevented the induction of LTD. $\boldsymbol{F}$, Pooled data to show that application of L-689,560 prevented the induction of LTD.

tive to blockade of NR2B-containing NMDARs. For this we chose RO 25-6981, which shows a $>1000$-fold selectivity for NR2B- over NR2A-containing NMDARs, and has not been demonstrated to inhibit the NR2A subunit until a concentration of $10 \mu \mathrm{M}$ is reached (Volianskis et al., 2013). We found that the bath application of the NR2Bselective antagonist RO 25-6981 (1 $\mu \mathrm{M})$ did not prevent the induction of LTD $\left(64 \% \pm 10 \%, \mathrm{df}=4, p=0.012^{\mathrm{m}}, N\right.$ $=5$; Fig. $3 A$ ). The next obvious step was to determine whether NR2A-containing NMDARs might be required for LTD at the LA-PRh synapse. Blockade of NR2A- containing NMDARs was achieved by the bath application of NVP-AAM077 at a concentration (200 nM) shown to be selective for NR2A- over NR2B-subunit-containing NMDARs (Bartlett et al., 2007). Indeed, we observed that the pharmacological blockade of NR2A-containing NMDARs prevented the induction of LTD $(98 \pm 12 \%$, df $=$ $4, p=0.054^{n}, N=5$; Fig. $3 B$ ). To confirm a role for NR2A-containing NMDARs in LTD, we repeated the experiment with a structurally dissimilar NR2A antagonist. For this, we utilised TCN-201 $(10 \mu \mathrm{M})$. This compound displays a $>1000$-fold selectivity for NR1/NR2A over 
A

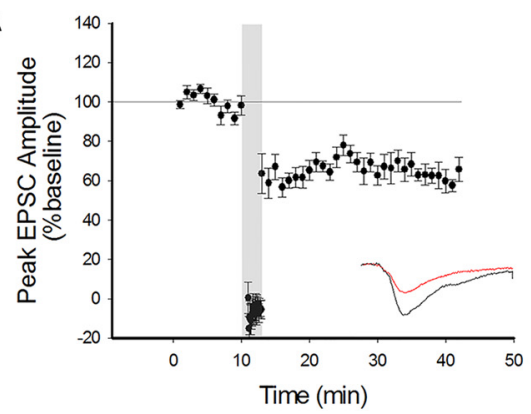

C

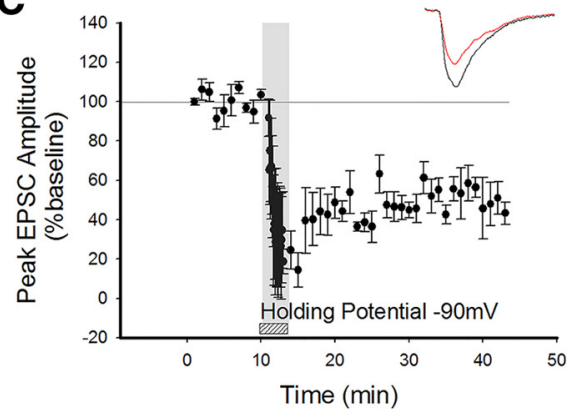

D

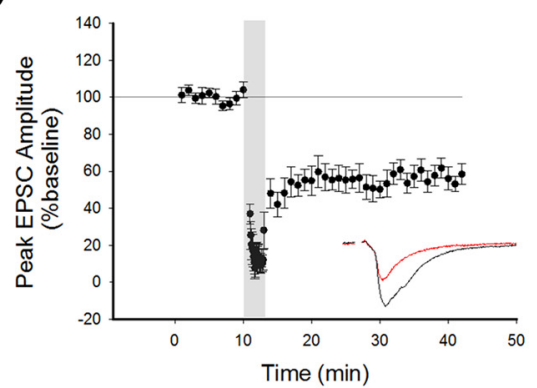

B

B1

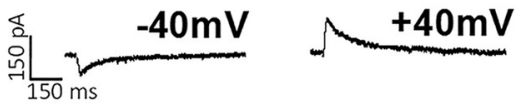

B2

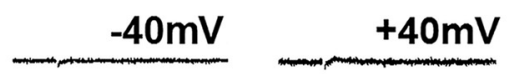

B3

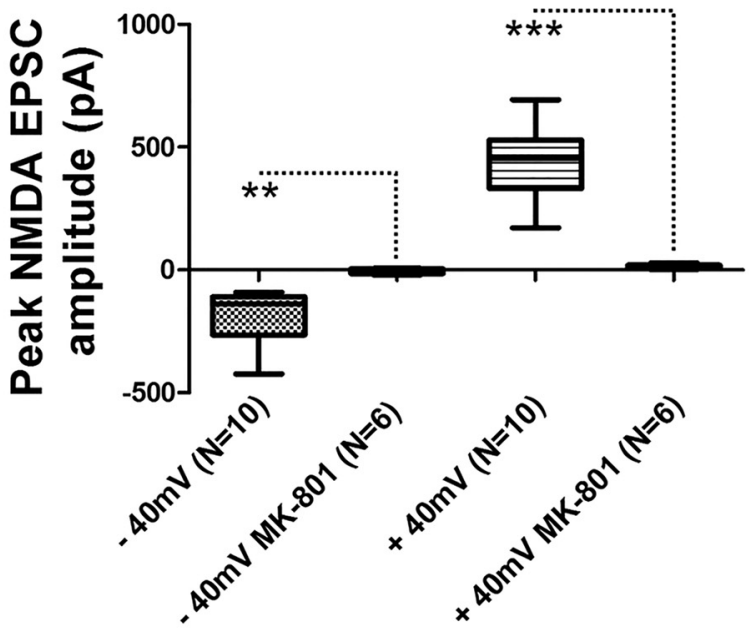

Figure 2 Blockade of postsynaptic NMDARs did not prevent the induction of LTD. $\boldsymbol{A}$, Application of the NMDAR pore-channel blocker MK-801 to the internal patch solution did not prevent LFS from inducing LTD. $\boldsymbol{B}$, Control experiment demonstrating that NMDAR currents could not be evoked when MK-801 was present in the internal patch solution. B1, B2, Traces of an NMDAR EPSC at -40 $\mathrm{mV}$ and $+40 \mathrm{mV}$ in the absence (B1) and presence (B2) of internal MK-801. B3, Box plot demonstrating the peak amplitude of the NMDAR response in the presence and absence of MK-801 in the internal patch solution. $\boldsymbol{C}$, Holding the cell at $-90 \mathrm{mV}$ during the delivery of LFS did not prevent the induction of LTD. $\boldsymbol{D}$, Application of the calcium chelator BAPTA to the internal patch solution did not prevent the induction of LTD. $* * p \leq 0.01, * * * p \leq 0.001$

NR1/NR2B, and at a concentration of $10 \mu \mathrm{M}$ has no reported antagonistic effect on NR2B-containing NMDARs (Edman et al., 2012; Hansen et al., 2014). We found that the application of TCN-201 also prevented the induction of LTD $\left(94 \pm 8 \%\right.$, df $=3, p=0.22^{\circ}, N=4$; Fig. $3 C)$.

Overall, our data suggested that the induction of LTD at the LA-PRh input relies on the activation of presynaptic NR2A-containing NMDARs. Previous work demonstrating a role for presynaptic NMDARs in the visual cortex has suggested that activity of cannabinoid CB1 receptors, coincident with presynaptic NMDAR activity, is essential for LTD (Sjöström et al., 2003). However, under the conditions of our experiments, postsynaptic BAPTA did not prevent LTD (Fig. 2D), and therefore, it is unlikely that a retrograde signal from the postsynaptic cell (that relies on postsynaptic calcium) is involved in the induction of LTD at the LA-PRh synapse. Nevertheless, we examined whether there may be a role for cannabinoid signaling by using the CB1 antagonist AM251 (1 $\mu \mathrm{M})$. However, we found that the induction of LTD was not blocked by bath application of AM251 $\left(71 \pm 12 \%, \mathrm{df}=4, p=0.034^{\mathrm{P}}, N=\right.$ 5; Fig. $3 D$ ). The structurally dissimilar $\mathrm{CB} 1$ receptor antagonist LY320135 $(5 \mu \mathrm{M})$ also had no effect on the induction of LTD ( $58 \pm 8 \%$, df $=2, p=0.044^{q}, N=3$; data not shown). Therefore, retrograde signalling (at least via cannabinoid receptors or triggered by a postsynaptic rise in calcium) is not required to be coincident with presynaptic NMDAR activation in order for LTD to be induced at the LA-PRh synapse.

Finally, to gain some insight into the locus of expression of LTD, we examined how LTD affects paired-pulse facil- 
A

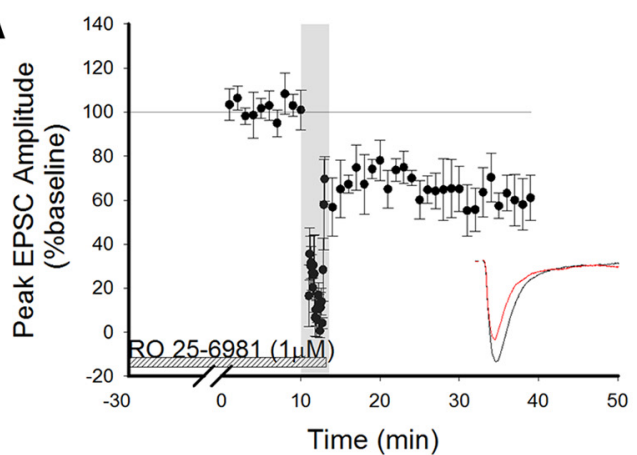

C

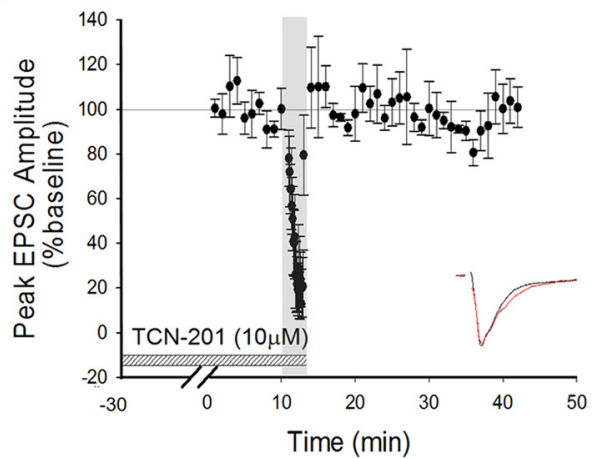

$\mathbf{E}$

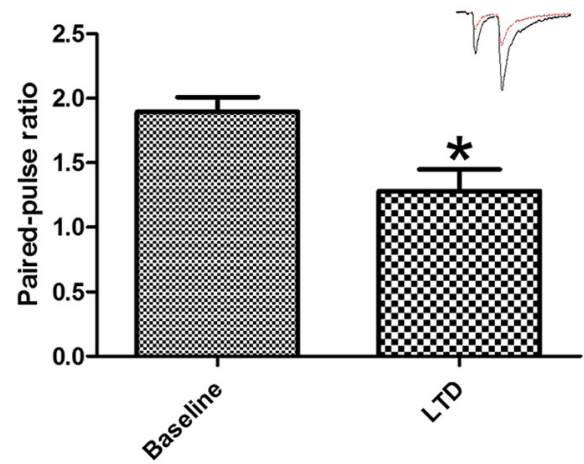

B

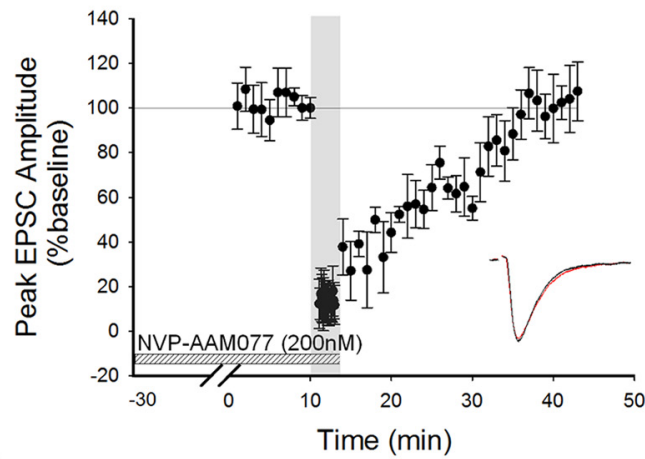

D

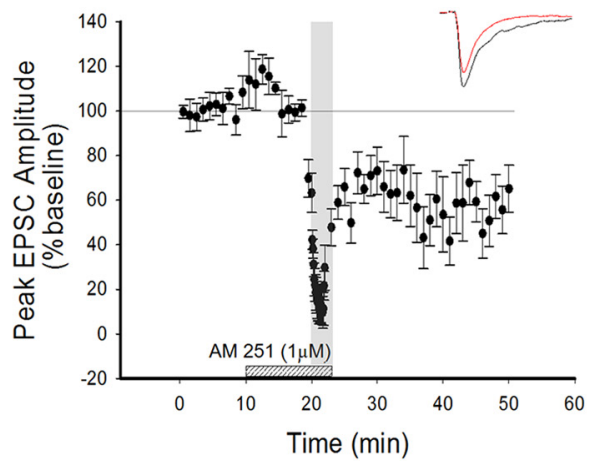

Figure 3 LTD induction relies on NR2A- but not NR2B-containing NMDARs. A, Bath application of the NR2B-selective antagonist RO 25-6981 did not prevent the induction of LTD. B. Bath application of the NR2A-selective antagonist NVP-AAM077 prevented the induction of LTD. C, Bath application of the NR2A-selective antagonist TCN-201 prevented the induction of LTD. $\boldsymbol{D}$, Bath application of the CB1R antagonist AM 251 did not prevent the induction of LTD. $E$, Paired-pulse facilitation is observed at the LA-PRh input during baseline recording and 30 min post-LFS. However, the facilitation is reduced by the delivery of the LFS protocol. $* p<0.05$.

itation (PPF). We found that 30 min following the induction of LTD, PPF $(1.3 \pm 0.15)$ was significantly reduced compared to basal conditions $\left(1.9 \pm 0.1, N=7, p=0.023^{r}\right.$, $\mathrm{df}=6, N=7$; Fig. 3E; Table 1).

\section{Discussion}

The amygdala has an established role in fear conditioning (Blair et al., 2001; Schafe et al., 2001; Maren and Quirk, 2004; Johansen et al., 2010), with information for these events being stored in the amygdala as a result of synaptic plasticity (Rogan et al., 1997; Fanselow and LeDoux, 1999; Blair et al., 2001). However, a less well defined, yet highly important role, of the amygdala is its ability to influence other forms of memory, particularly when the learning episode has a degree of emotional salience (Paz et al., 2006). The mechanisms by which the lateral amygdala modulates LTP in the perirhinal cortex have only recently been described (Laing and Bashir, 2014), and this paper expands our understanding of these mechanistic processes by studying the receptor mechanisms required for amygdala-perirhinal LTD.

We observed that LTD between the lateral amygdala and layer II/III of the perirhinal cortex is NMDARdependent and does not rely on $\beta$-ADRs or VGCCs. This is in contrast to LTP between the lateral amygdala and perirhinal cortex, which is NMDAR-independent and $\beta$-ADRs/VGCC-dependent (Perugini et al., 2012; Laing and Bashir, 2014). Therefore, the mechanisms of induction for LTP and LTD at the same input from the lateral amygdala to the perirhinal cortex are very different. 


\section{Table 1: Statistical table}

\begin{tabular}{llll}
\hline & Data structure & Type of test & $p$ value \\
a & Normal distribution & Paired $t$ test & 0.0045 \\
b & Normal distribution & Paired $t$ test & 0.6 \\
c & Normal distribution & Paired T test & 0.01 \\
d & Normal distribution & Paired $t$ test & 0.0089 \\
e & Normal distribution & Paired $t$ test & 0.16 \\
f & Normal distribution & Paired $t$ test & 0.41 \\
g & Normal distribution & Paired $t$ test & 0.029 \\
h & Normal distribution & Unpaired $t$ test & 0.92 \\
i & Normal distribution & Unpaired $t$ test & 0.0015 \\
j & Normal distribution & Unpaired $t$ test & $\leq 0.0001$ \\
k & Normal distribution & Paired $t$ test & 0.028 \\
l & Normal distribution & Paired $t$ test & $\leq 0.0001$ \\
m & Normal distribution & Paired $t$ test & 0.012 \\
$\mathrm{n}$ & Normal distribution & Paired $t$ test & 0.054 \\
o & Normal distribution & Paired $t$ test & 0.22 \\
p & Normal distribution & Paired $t$ test & 0.034 \\
q & Normal distribution & Paired $t$ test & 0.044 \\
r & Normal distribution & Unpaired $t$ test & 0.023 \\
\hline
\end{tabular}

Surprisingly, we found that although the induction of LTD relied on the activation of NMDARs, postsynaptic mechanisms do not appear to play a role in LTD induction at the LA-PRh input. Thus, neither a high concentration of BAPTA in the postsynaptic cell, nor blockade of postsynaptic NMDARs by MK-801 loaded in the patch pipette, nor hyperpolarising the postsynaptic neuron to maintain the $\mathrm{Mg}^{2+}$ block of the NMDAR channel resulted in a block of LTD. Therefore, a simple conclusion from these results is that the NMDARs crucial for the induction of LTD are presynaptically located.

A recent study in hippocampus (Nabavi et al., 2013) reported that the competitive NMDAR antagonist AP5 prevented the induction of LTD but that MK-801 or glycine site antagonists did not block LTD and suggested a metabotropic function of NMDARs in LTD (but see Babiec et al., 2014). While these results are similar in some respects to our findings, there is an important difference: in our study, the glycine site antagonist blocked the induction of LTD. Therefore, in agreement with Babiec et al. (2014), NMDAR activation in our study most likely relies on canonical NMDARs, rather than metabotropic NMDARs.

Several studies have provided evidence for the importance of presynaptic NMDARs in the induction of LTD (Sjöström et al., 2003; Lien et al., 2006; Corlew et al., 2007; Brasier and Feldman, 2008; Rodríguez-Moreno and Paulsen, 2008). It has been suggested that the presynaptic NMDARs responsible for LTD in the visual cortex are NR2B-subunit containing. However, in our current work, the NR2B antagonist RO 25-6981 did not block LTD at the LA-PRh input. Interestingly, a role for retrograde cannabinoid signaling following a postsynaptic rise in calcium was postulated to be important for induction of LTD, where NR2B-NMDARs were shown to be required (Sjöström et al., 2003). Though, in our study, inhibitors of CB1 receptors did not affect LTD, and neither did LTD rely on a rise in postsynaptic calcium. It is unlikely, therefore, that cannabinoids generated postsynaptically, or from other sources, are necessary for the induction of LTD.
In contrast to the above studies in visual cortex, we found that two different antagonists of NR2A-containing NMDARs blocked the induction of LTD. Therefore, it is most likely that presynaptic NR2A-containing NMDARs are responsible for the induction of LTD at the LA-PRh input. These results are in contrast to the postsynaptic NR2B-NMDAR mechanisms for LTD that have been described at intracortical PRh synapses (Massey et al., 2004) and that are considered to be essential for visual recognition memory (Griffiths et al., 2008). Overall, this demonstrates that LTD at different inputs to the perirhinal cortex can rely on very different receptor mechanisms for the induction of plasticity.

Indeed, it has been demonstrated that LTD at two different inputs onto layer II neurons in the visual cortex relied on two different mechanisms (Larsen et al., 2014). Activation of presynaptic NR2A-containing NMDARs were shown as necessary for LTD at the parallel fiber-purkinje cell synapse, and it has been suggested that the role of these presynaptic receptors is to detect the temporal patterns of presynaptic action potential firing. Thus, it is possible that intracortical PRh synapses, that encode recognition memory, rely on Hebbian integration mechanisms but that LA-PRh synapses rely on the temporal structure of presynaptic action potential firing to modulate recognition memory.

A reasonable question to ask is whether NR3containing NMDARs may have any role in the LTD observed in this study, considering that these receptors have demonstrated importance in presynaptic plasticity (Corlew et al., 2008). To date, we know very little about this synapse, and we know, overall, little about presynaptic mechanisms and physiological functions of NR3containing NMDARs. However, in this study, we believe NR3-containing NMDARs are unlikely to contribute to the LTD observed (either as NR1/NR3 or as NR1/NR2/NR3).

A comparison of NR1 or NR2 versus NR3 shows $\sim 24 \%$ sequence homology, with structural differences that suggest a very different pharmacological binding profile (Monaghan and Jane, 2009). As an example, L689,560, which blocked LTD, is strongly selective for NR1- over NR3-containing NMDARs binding with nanomolar affinity (Yao and Mayer, 2006). Also, TCN-201 (which blocked LTD) inhibition is mediated by residues from both NR1 and NR2A subunits (Edman et al., 2012) and can only inhibit NMDARs via interaction with the dimer interface between NR1/NR2A. It is also worth highlighting that NR3 expression starts to decrease around the time of eye opening (Bendová et al., 2009), with low immunohistochemical expression of NR3 past P21, and remaining low into adulthood (Sucher et al., 1995). Further, in vitro electrophysiology has observed no significant NR3 contribution to NMDA-activated currents past P11-P13 (Sasaki et al., 2002).

The work presented here demonstrates the complexity of plastic mechanisms between the lateral amygdala and the perirhinal cortex. While underpinning some of the key receptor mechanisms involved in the induction of LTD at this synapse, we leave further avenues of research available for future studies to establish. Though it is beyond 
the scope of this paper to also study the mechanisms by which LTD expression occurs, our observation that paired-pulse facilitation is reduced at this synapse following LTD at least highlights a presynaptic role for the expression of LTD. However, the change in the PPF following the induction of LTD was unexpected, as a presynaptic mechanism for LTD would be expected to decrease transmitter release, which is classically associated with an increase in PPF.

One possibility that explains our findings is that the release of glutamate following the first stimulus binds presynaptic NMDARs, so that during the second stimulus NMDARs are activated and lead to an increase in the presynaptic calcium entry that contributes significantly to the PPF. A presynaptic decrease in transmitter release, following LTD, would then result in less activation of NMDARs during the second stimulus, reduced calcium entry, and therefore, a decrease in PPF. In support of this possibility, Berretta and Jones (1996) observed in the entorhinal cortex an approximate $20 \%$ reduction in paired-pulse facilitation during superfusion with D-AP5 (while blocking postsynaptic NMDARs with MK-801 in the patch pipette).

Overall, in this paper we provide fundamental insights into the basic mechanisms of LTD induction at this synapse. We have demonstrated that LTD between the lateral amygdala and layer II/III of the perirhinal cortex is induced presynaptically via NR2A-containing NMDARs, and we expand on current literature, which demonstrates the receptor mechanisms of LTP between these two regions (Perugini et al., 2012; Laing and Bashir, 2014). The combination of this body of research demonstrates that the receptors required for LTD and LTP at the LA-PRh input are NMDAR-dependent and NMDAR-independent, respectively. Potentially, the requirement for $\beta$-ADRs in LTP (Laing and Bashir, 2014) but not in LTD, as demonstrated here, suggests that emotional stimuli will impact synaptic events in a differential manner.

\section{References}

Aggleton JP, Keen S, Warburton EC, Bussey TJ (1997) Extensive cytotoxic lesions involving both the rhinal cortices and area TE impair recognition but spare spatial alternation in the rat. Brain Res Bull 43:279-287. Medline

Babiec WE, Guglietta R, Jami SA, Morishita W, Malenka RC, O'Dell TJ (2014) lonotropic NMDA receptor signaling is required for the induction of long-term depression in the mouse hippocampal CA1 region. J Neurosci 34:5285-5290. CrossRef Medline

Bartlett TE, Bannister NJ, Collett VJ, Dargan SL, Massey PV, Bortolotto ZA, Fitzjohn SM, Bashir ZI, Collingridge GL, Lodge D (2007) Differential roles of NR2A and NR2B-containing NMDA receptors in LTP and LTD in the CA1 region of two-week old rat hippocampus. Neuropharmacology 52:60-70. CrossRef Medline

Bendová Z, Sumová A, Mikkelsen JD (2009) adian and developmental regulation of $\mathrm{N}$-methyl-d-aspartate-receptor $1 \mathrm{mRNA}$ splice variants and $\mathrm{N}$-methyl-d-aspartate-receptor 3 subunit expression within the rat suprachiasmatic nucleus. Neuroscience 159:599609. CrossRef

Berretta N, Jones RS (1996) Tonic facilitation of glutamate release by presynaptic N-methyl-D-aspartate autoreceptors in the entorhinal cortex. Neuroscience 75:339-344. Medline
Blair HT, Schafe GE, Bauer EP, Rodrigues SM, LeDoux JE (2001) Synaptic plasticity in the lateral amygdala: a cellular hypothesis of fear conditioning. Learn Mem 8:229-242. CrossRef

Brasier DJ, Feldman DE (2008) Synapse-specific expression of functional presynaptic NMDA receptors in rat somatosensory cortex. $J$ Neurosci 28:2199-2211. CrossRef Medline

Brown MW, Xiang JZ (1998) Recognition memory: neuronal substrates of the judgement of prior occurrence. Prog Neurobiol 55:149-189. Medline

Cho K, Kemp N, Noel J, Aggleton JP, Brown MW, Bashir ZI (2000) A new form of long-term depression in the perirhinal cortex. Nat Neurosci 3:150-156. CrossRef Medline

Corlew R, Wang Y, Ghermazien H, Erisir A, Philpot BD (2007) Developmental switch in the contribution of presynaptic and postsynaptic NMDA receptors to long-term depression. J Neurosci 27: 9835-9845. CrossRef Medline

Corlew R, Brasier DJ, Feldman DE, Philpot BD (2008) Presynaptic NMDA receptors: newly appreciated roles in cortical synaptic function and plasticity. Neuroscientist 14:609-625. CrossRef Medline

Dix SL, Aggleton JP (1999) Extending the spontaneous preference test of recognition: evidence of object-location and object-context recognition. Behav Brain Res 99:191-200. Medline

Edman S, McKay S, Macdonald LJ, Samadi M, Livesey MR, Hardingham GE, Wyllie DJ (2012) TCN 201 selectively blocks GluN2Acontaining NMDARs in a GluN1 co-agonist dependent but noncompetitive manner. Neuropharmacology 63:441-449. CrossRef Medline

Ennaceur A, Aggleton JP (1997) The effects of neurotoxic lesions of the perirhinal cortex combined to fornix transection on object recognition memory in the rat. Behav Brain Res 181-193. CrossRef

Ennaceur A, Neave N, Aggleton JP (1997) Spontaneous object recognition and object location memory in rats: the effects of lesions in the cingulate cortices, the medial prefrontal cortex, the cingulum bundle and the fornix. Exp Brain Res 113:509-519. Medline

Fahy FL, Riches IP, Brown MW (1993) Neuronal activity related to visual recognition memory: long-term memory and the encoding of recency and familiarity information in the primate anterior and medial inferior temporal and rhinal cortex. Exp Brain Res 96:457472. Medline

Fanselow SM, LeDoux JE (1999) Why we think plasticity underlying pavlovian fear conditioning occurs in the basolateral amygdala. Neuron 229-232. Medline

Furtak SC, Allen TA, Brown TH (2007) Single-unit firing in rat perirhinal cortex caused by fear conditioning to arbitrary and ecological stimuli. J Neurosci 12277-12291. CrossRef Medline

Gaffan D, Murray EA (1992) Monkeys (Macaca fascicularis) with rhinal cortex ablations succeed in object discrimination learning despite 24-hr intertrial intervals and fail at matching to sample despite double sample presentations. Behav Neurosci 106:30-38. Medline

Griffiths S, Scott H, Glover C, Bienemann A, Ghorbel MT, Uney J, Brown MW, Warburton EC, Bashir ZI (2008) Expression of longterm depression underlies visual recognition memory. Neuron 58: 186-194. CrossRef

Hansen KB, Ogden KK, Yuan H, Traynelis SF (2014) Distinct functional and pharmacological properties of Triheteromeric GluN1/ GluN2A/GluN2B NMDA receptors. Neuron 81:1084-1096. CrossRef Medline

Johansen JP, Hamanaka H, Monfils MH, Behnia R, Deisseroth K, Blair HT, LeDoux JE (2010) Optical activation of lateral amygdala pyramidal cells instructs associative fear learning. Proc Natl Acad Sci U S A 107:12692-12697. CrossRef

Kajiwara R, Takashima I, Mimura Y, Witter MP, lijima T (2003) Amygdala input promotes spread of excitatory neural activity from perirhinal cortex to the entorhinal-hippocampal circuit. J Neurophysiol 89:2176-2184

Laing M, Bashir ZI (2014) $\beta$-Adrenoceptors and synaptic plasticity in the perirhinal cortex. Neuroscience 273:163-173. CrossRef Medline 
Larsen RS, Smith IT, Miriyala J, Han JE, Corlew RJ, Smith SL, Philpot BD (2014) Synapse-specific control of experience-dependent plasticity by presynaptic NMDA receptors. Neuron 83:879-893. CrossRef Medline

Lien CC, Mu Y, Vargas-Caballero M, Poo MM (2006) Visual stimuliinduced LTD of GABAergic synapses mediated by presynaptic NMDA receptors. Nat Neurosci 9:372-380. CrossRef Medline

Maren S, Quirk GJ (2004) Neuronal signalling of fear memory. Rev Neurosci 844-852. CrossRef Medline

Massey PV, Johnson BE, Moult PR, Auberson YP, Brown MW, Molnar E, Collingridge GL, Bashir ZI (2004) Differential roles of NR2A and NR2B-containing NMDA receptors in cortical long-term potentiation and long-term depression. J Neurosci 24:7821-7828. CrossRef

Massey PV, Phythian D, Narduzzo K, Warburton EC, Brown MW, Bashir ZI (2008) Learning-specific changes in long-term depression in adult perirhinal cortex. J Neurosci 28:7548-7554. CrossRef

Monaghan DT, Jane DE (2009) Pharmacology of NMDA receptors. In: Biology of the NMDA receptor: frontiers in neuroscience (Van Dongen AM, ed). Boca Raton, FL: CRC.

Murray EA, Bussey TJ (1999) Perceptual-mnemonic functions of the perirhinal cortex. Trends Cogn Sci 3:142-151. CrossRef

Nabavi S, Fox R, Alfonso S, Aow J, Malinow R (2013) GluA1 trafficking and metabotropic NMDA: addressing results from other laboratories inconsistent with ours. Philos Trans R Soc Lond B Biol Sci 369:20130145. CrossRef

Paoletti P, Neyton J (2007) NMDA receptor subunits: function and pharmacology. Curr Opin Pharmacol 7:39-47. CrossRef Medline

Paz R, Pelletier JG, Bauer EP, Paré D (2006) Emotional enhancement of memory via amygdala-driven facilitation of rhinal interactions. Nat Neurosci 9:1321-1329. CrossRef Medline

Perugini A, Laing M, Berretta N, Aicardi G, Bashir ZI (2012) Synaptic plasticity from amygdala to perirhinal cortex: a possible mechanism for emotional enhancement of visual recognition memory? Eur J Neurosci 36:2421-2417. CrossRef

Pitkänen A, Pikkarainen M, Nurminen N, Ylinen A (2000) Reciprocal connections between the amygdala and the hippocampal formation, perirhinal cortex, and postrhinal cortex in rat. Ann N Y Acad Sci 911:369-391. CrossRef

Rodríguez-Moreno A, Paulsen O (2008) Spike timing-dependent long-term depression requires presynaptic NMDA receptors. Nat Neurosci 11:744-745. CrossRef Medline

Rogan MT, Stäubli UV, LeDoux JE (1997) Fear conditioning induces associative long-term potentiation in the amygdala. Nature 390: 604-607. CrossRef

Roozendaal B, Castello NA, Vedana G, Barsegyan A, McGaugh JL (2008) Noradrenergic activation of the basolateral amygdala mod- ulates consolidation of object recognition memory. Neurobiol Learn Mem 90:576-579.

Sasaki YF, Rothe T, Premkumar LS, Das S, Cui J, Talantova MV, Wong HK, Gong X, Chan SF, Zhang D, Nakanishi N, Sucher NJ, Lipton SA (2002) Characterization and comparison of the NR3A subunit of the NMDA receptor in recombinant systems and primary cortical neurons. J Neurophysiol 87:2052-2063. CrossRef Medline

Schafe GE, Nader K, Blair HT, LeDoux JE (2001) Memory consolidation of Pavlovian fear conditioning: a cellular and molecular perspective. Trends Neurosci 24:540-546.

Sjöström PJ, Turrigiano GG, Nelson SB (2003) Neocortical LTD via coincident activation of presynaptic NMDA and cannabinoid receptors. Neuron 39:641-654. Medline

Sucher NJ, Akbarian S, Chi CL, Leclerc CL, Awobuluyi M, Deitcher DL, Wu MK, Yuan JP, Jones EG, Lipton SA (1995) Developmental and regional expression pattern of a novel NMDA receptor-like subunit (NMDAR-L) in the rodent brain. J Neurosci 15:6509-6520. Medline

Suzuki WA (1996) The anatomy, physiology and functions of the perirhinal cortex. Curr Opin Neurobiol 6:179-186. Medline

Suzuki WA, Zola-Morgan S, Squire LR, Amaral DG (1993) Lesions of the perirhinal and parahippocampal cortices in the monkey produce long-lasting memory impairment in the visual and tactual modalities. J Neurosci 13:2430-2451.

Volianskis A, Bannister N, Collett VJ, Irvine MW, Monaghan DT, Fitzjohn SM, Jensen MS, Jane DE, Collingridge GL (2013) Different NMDA receptor subtypes mediate induction of long-term potentiation and two forms of short-term potentiation at CA1 synapses in rat hippocampus in vitro. J Physiol 15:955-972. CrossRef

Warburton EC, Koder T, Cho K, Massey PV, Duguid G, Barker GR, Aggleton JP, Bashir ZI, Brown MW (2003) Cholinergic neurotransmission is essential for perirhinal cortical plasticity and recognition memory. Neuron 38:987-996. CrossRef

Winters BD, Forwood SE, Cowell RA, Saksida LM, Bussey TJ (2004) Double dissociation between the effects of peri-postrhinal cortex and hippocampal lesions on tests of object recognition and spatial memory: heterogeneity of function within the temporal lobe. $\mathrm{J}$ Neurosci 24:5901-5908. CrossRef Medline

Yao Y, Mayer ML (2006) Characterization of a soluble ligand binding domain of the NMDA receptor regulatory subunit NR3A. J Neurosci 26:4559-4566. CrossRef Medline

Zhu XO, Brown MW (1995) Changes in neuronal activity related to the repetition and relative familiarity of visual stimuli in rhinal and adjacent cortex of the anaesthetised rat. Brain Res 689:101-110. Medline 